Case Report

\title{
Extensive Ameloblastoma of the Mandible
}

\author{
Md. Obaidur R Chowdhury', Saiful Islam², W R Chowdhury. M E Haque ${ }^{4}$
}

\begin{abstract}
The ameloblastoma is the most common and aggressive odontogenio tumour of the jaws. But only rarely the anterior portions of the jaws are involved. Since extensive ameloblastoma of the mandible crossing the symphysis upto the canine region of the opposite site is a rare occurrence, so we are encouraged to present this case for academic interest.
\end{abstract}

TAJ 2002; 15(2): 93-95

\section{Introduction}

The ameloblastoma is the most common and aggressive odontogenic tumour of the jaws ${ }^{1.2 .3}$ It is a true neoplasm, generally considered to be a benign but persistent lesion. However, some authors consider this tumour to be a locally malignant lesion on the basis of persistent local growth $^{4.5}$. The suggested aetiology of ameloblastoma is that it either arises from the dental lamina or more probably, it arises from basal cells of the oral epithelium or from cells that have undergone differentiation to mimic the ameloblast ${ }^{6}$. The ameloblastoma usually occurs in persons between the age of 20 and 50 years with the average age being 39 years. About $80 \%$ occur in the mandible and the remainder in the maxilla. In both the mandible and the maxilla, the majority $(80 \%)$ is located in the molar area and a few $(10 \%$ to $20 \%$ ) in the premolar area. Only rarely the anterior portions of the jaws are involved ${ }^{\top}$. Since extensive ameloblastoma of the mandible crossing the symphysis upto the canine region of the opposite site is a rare occurrence, so we are encouraged to present this case for academic interest.

\section{Case Report}

A 22 year old married female, hailing from Baghmara , Rajshahi was admitted in to the surgery unit - II of Rajshahi Medical College Hospital on 27-06-2002 with complaints of asymmetry of the face due to massive swelling in the lower right jaw, The patient stated that she had noticed this gradually growing tumour mass during the past 5 years causing a noticeable facial deformity. The patient was transferred to ENT ward, RMCH for radical oral surgery. Extraonilly on examination, a firm, non-tender, diffese swelling involving the entire right mandible if $f=1$ and Fig 1.a) measured approximately $10 \times 8 \mathrm{~cm}$ was detected. Intraorally, an oval mass of tisese measuring $6 \times 6 \mathrm{~cm}$. was seen from the $\mathrm{nd}=$ ascending ramus upto midline of the mancist with loosening and displacement of teeth. $\mathrm{nx}$ colour of the mucosa was normal bes shesel cuspal indentation from the upper tecth

Panoramic view (Orthopantolsogramivut the mandible revealed large multilocale seas of radiolucency involving whole w the nith

\footnotetext{
Assistant Professor, Deparment of Oral Surgery, Dental unit. Rajshahi Medical College, Rajshahi-6000, Bangladest!

z Assistant Professor, Department of ENT, Rajshahi Medical College, Rajshahl-6000, Bangladesh.

2Lacturer, Department of Oral Surgery, Dental unit, Rajshahi Medicai College, Rajshahi -6000, Bangladesh.

- Assistant Professor. Department of Anaesthesialogy. Dental unit. Rajshahi Medical Colege. Rajshahi-6000, Bangladent.
} 


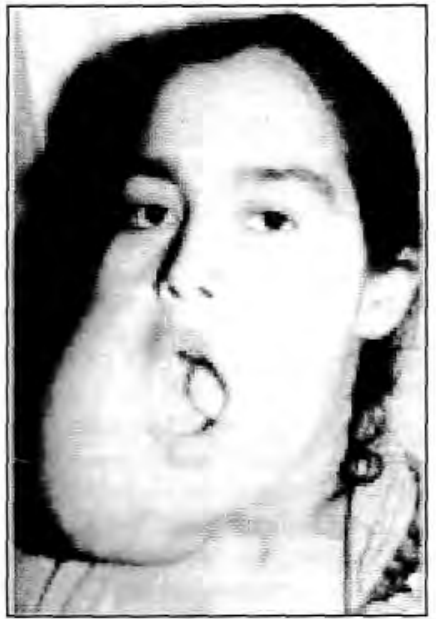

Fig. 1. Clinical Photograph Showing a Large ameloblastoma.

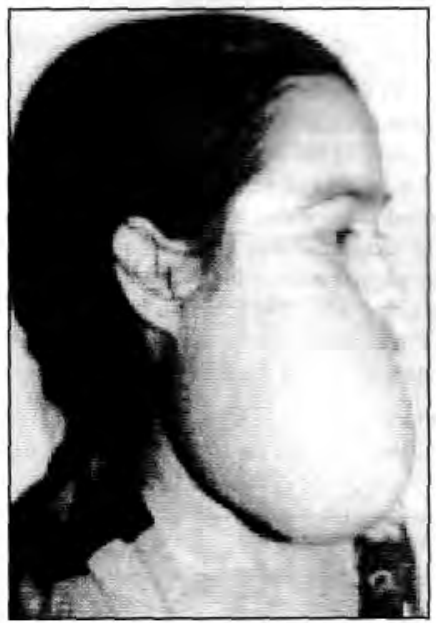

Fig. 1.a

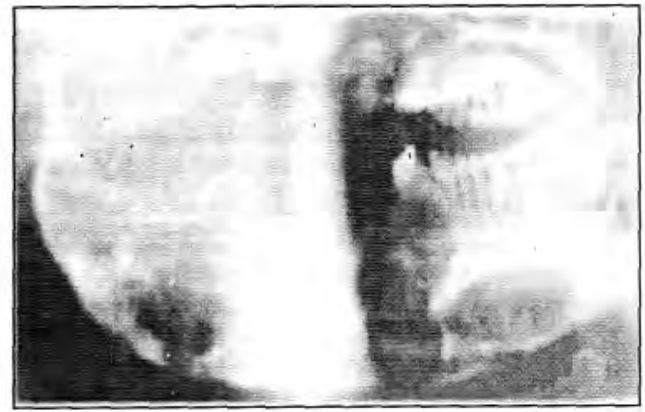

Fig. 2. Panoramic View (Orthopantomogram) of the Mandible showing multicystic areas of radiolucency with expansion and thining of the cortical bones.

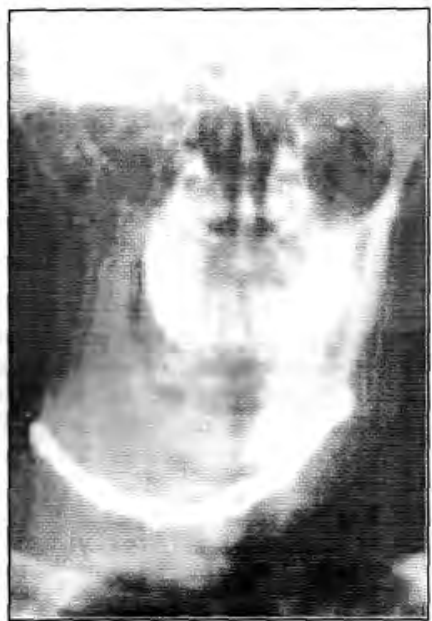

Fig. 3, P.A. View of the mandible after operation with metalic plate and screws. 
mandible extending upto lower left canine area (Fig.2). The labial cortical plate was expanded and thinned. There were small cystic areas in or around the larger cystlike areas. This lesion simulates the radiographic appearance of an ameloblastoma. Hemimandibulectorny under general anaesthesia was performed and reconstruction was done with metallic plate and screws (Fig. 3). The patient was given nasogastric feedings for 5 days with usual postoperative antibiotics and analgesics. Later on, diagnosis of ameloblastoma was confirmed by histopathology.

\section{Discussion}

Extensive ameloblasioma of the mandible causing severe facial deformity is really disfiguring condition with unbearable social problem. This poor woman stated that her husband started living separately and got married to another one because of her ugly looking facial deformity. The sociocultural fuct that was revealed out of this condition is really unfortunate. Had it been diagnosed earlier, there would have been much better scopes for post-operative functional and cosmetic results.

The treatment of the ameloblastoma ranges from conservative curettage to radical resection of the tumour. In most instances, the early literature advocated conservative treatment eonsisting of simple enucleation from an intracoral approach. Because of the high recurrence rate in conservative method of treatment, the pendulum at this time appears to have swung toward a more radical surgical approach. Successful treatment is a difficull term to define because the recurrence of the tumour does not always necessarily indicate that the treatment was unsuccessful. Sometimes, radical resection may be difficult to justify when a less extensive procedure will maintain functional and cosmetic results for more than 20 years ${ }^{8}$ Again it is also equally difficult to justify in an elderly patient who has impaired general health because the radical treatment might cause situation worsen than the disease itself. On the other hand, conservative treatment cannot be justified if recurrence is likely within a short time.

\section{Conclusion}

Since the ameloblastoma is locally invasive, destructive and clinically malignant tumour, the only rational treatment is complete surgical removal. And if the lesion is very extensive, radical resection of the involved bone with or without immediate reconstruction is the treatment of choice. As far as possible, immediate reconstruction must be planned to restore the function and aesthetics.

\section{References}

1. Gorlin A J, Chaudhury A P, Pindborg $J \mathrm{~J}$. Odontogenic tumours: classification, histopathology and clinical behaviour in man and domesticated animals. Cancer 1961; 14:73.

2. Small I A, Waldrom C A Ameloblastoma of the jaws. Oral Surg 1955, 8:281

3. Taylor B G. Ameloblastoma of the mandible: a clinical study of twenty-five patients. Am J Surg. 1968, 34:57.

4. Caldwell T A. Separsky M S. Luccbesi F J. Immediate mandibular reconstruction with iliac bone after surgery for ameloblastoma. I Oral Surg 1970; $28: 386$.

5. Shatkin $\mathrm{S}$, Hotfmeister F S. Ameloblastoma: a rational approach to therapy. 5 Oral Surg 1965: 20:421.

6. Smith $\rfloor \mathrm{F}$. The controversial ameloblastoma. $J$ Oral Surg 1968; 26:45.

7. Bhaskar S N. Synopsis of oral pathology, St Louis, Mosby Co., First Indian Edition, 1990; 263.

8. Mehlisch D R, Dahlin D C, Masson $J \mathrm{~K}$ Ameloblastoma $=$ a clinicopathologic report. $J$ Ora/ Surg 1972; 30:9.

All correspondence ta: Dr.Md. Obaidur R. Chowdhary Assistant Prolessoi Department of Oral Surgery Dental Unit, Rajshahi Medical College Rajshahi-6000, Bangladeah. 